\title{
Generación Z: Ios universitarios del bicentenario
}

\author{
Generation Z: the university students of the bicentennial
}

\author{
Mónica Soto del Águila \\ Universidad de Lima
}

\section{RESUMEN}

El artículo se enfoca en revisar los cambios generacionales como procesos inherentes a la evolución del ser humano, en el marco de los cuales cada generación se centra en su propia forma de ver y hacer las cosas en los distintos dominios vitales. Se describen las principales características que hacen "diferentes" a los hoy adolescentes de la generación Z (nacidos alrededor del cambio de milenio) y sus implicancias en el aprendizaje; como, por ejemplo, su preferencia por el aprendizaje autodirigido sobre la base de la observación y la práctica, su estrecha relación con la tecnología, su escaso rango atencional y su permanente necesidad de gratificación instantánea. A través de un breve sondeo cualitativo, se intenta realizar una aproximación al conocimiento de estas características en estudiantes pertenecientes a este grupo etáreo, recogiendo sus vivencias y necesidades normativas. Aunque el cambio es una fuente de estrés para todo individuo, es un hecho que la tecnología está cambiando nuestros cerebros y sus habilidades, frente a lo cual es necesario percatarse de que el cambio y aquello que nos resulta nuevo no es malo, sino simplemente diferente.

\section{Palabras clave:}

generación Z, bicentenario, aprendizaje, adolescentes

\section{ABSTRACT}

This article aims at reviewing generational changes as processes inherent to the evolution of human beings, according to which each generation focuses on its own way of seeing and doing things in various vital domains. It describes the main characteristics that make "different" today's generation Z teens (those born around the turn of the millennium), and the implications of such characteristics on learning; for example, their preference for self-directed learning based on observation and practice, their close relationship with technology, their extremely low attention level, and their permanent need for instant gratification. An approach to understand said characteristics in students belonging to this age group was made through a brief qualitative survey in which their experiences and normative needs were collected. Even though changes are a source of stress for everyone, it is a fact that technology is changing our brains and skills. Considering this situation, it is necessary to realize that changes and everything new for us are not negative things, just different ones.

Key words:

generation Z, bicentennial, learning, teenagers 


\section{Introducción}

$\mathrm{M}$ i hija de tres años no quiere ir a cenar a la cocina porque "ahí no hay internet", mientras la de cinco, que ya lee y escribe, busca de manera autónoma los videos de personajes que desea ver en Youtube y Netflix (donde tiene su propio perfil). Son dos "nativas digitales ${ }^{1 "} y$, a tan corta edad, ya no pueden vivir sin la tecnología. Como Alondra, estudiante de 18 años, quien al preguntarle cómo se siente cuando no hay wifi, responde: "me siento incompleta". Estamos, definitivamente, frente a una población diferente, nueva, con intereses, gustos, habilidades y carencias distintas a las generaciones que la precedieron.

La generación Z, como se ha llamado a los hoy adolescentes que nacieron alrededor del cambio de milenio (Acha, 2012), está llegando a las aulas universitarias y resulta fundamental explorar, describir y valorar sus propias características en un contexto académico que, al mismo tiempo, exige cambios en los docentes, si apuntan a lograr determinados objetivos de aprendizaje en los jóvenes.

\section{Marco teórico}

\section{Origen}

Los cambios generacionales son inherentes a la evolución del ser humano. El contexto ambiental va cambiando $y$, por lo tanto, va desarrollando humanos distintos que, dentro de su individualidad, comparten ciertas características según la época en la cual crecen.

En este entorno de cambio constante, las personas, paradójicamente, nos resistimos a él, y nos cuesta incorporar nuevas formas de hacer algo que venía funcionando de manera aceptable o cómoda para nosotros. No solo rechazamos el cambio en nuestra vida (todo cambio, sea para bien o para mal, produce estrés y requiere de un ajuste personal), sino que tendemos a infravalorar el cambio en los demás. No es raro escuchar a alguien decir: "en mi época se pensaba más", "antes aprendíamos mejor, éramos más cultos", u otras frases en ese sentido que apelan al famoso dicho: "todo tiempo pasado fue mejor".
La invasión de la tecnología en todos los ámbitos de nuestra vida ha llevado a muchos "migrantes digitales" a establecer como premisa que aquello no contaminado por el internet y sus derivados es mejor, más puro o menos superficial. Tendemos a creer que las tecnologías afectan negativamente la función intelectual. Sin embargo, es importante mantener la objetividad frente a los cambios que venimos observando en cuanto a habilidades cognitivas y procesamiento mental. El doctor Ricardo Allegri, jefe de Neurología Cognitiva de la Fundación para la Lucha contra las Enfermedades Neurológicas de la Infancia (Fleni) en Argentina, afirma:

\begin{abstract}
Las nuevas tecnologías cambian paradigmas. De esta manera, las formas de procesamiento que eran habituales en generaciones anteriores empiezan a cambiar, es decir, si en el pasado el procesamiento de la información era más lineal, hoy el cerebro trabaja de otra manera, por eso las conversaciones hoy no son lineales, sino que se dan en paralelo, motivo por el cual una persona puede mantener al mismo tiempo varias conversaciones diferentes a través de Twitter, SMS y chat, sin inconvenientes. (como se citó en Slotnisky, 2012, p. 2)
\end{abstract}

Aunque es un campo aún en investigación, está claro que la adaptación del cerebro humano a la tecnología está afectando la manera en la que percibimos, procesamos y almacenamos información. El cerebro no deja de trabajar, sino que lo hace de una manera distinta (Slotnisky, 2012).

Todos estos cambios van configurando un nuevo ser humano que desarrolla nuevas capacidades cerebrales, mientras desecha otras que van quedando obsoletas; cambios que han sido enmarcados desde hace buen tiempo en una clasificación por "generaciones".

El estudio sobre generaciones sociales ha tenido siempre un origen estadounidense, generalmente promovido por profesionales vinculados a la publicidad y a la sociología (Romero, 2014). Es así como se han clasificado sucesivamente distintas generaciones desde la etapa posterior a la segunda guerra mundial hasta nuestros días, siglo xxı. Primero fueron los baby boomers (nacidos entre 1945 y 1964), luego la generación X (1965-1980) y después los millennials o generación Y (1981-mediados de los noventa). Hoy surge la nueva categoría generacional conocida como generación Z

No existe un acuerdo sobre el año de nacimiento correspondiente a la generación Z. Algunos autores le dan un

1 Término acuñado por el autor estadounidense Marc Prensky en el 2001. 
rango amplio: los nacidos entre 1994 y 2012 (Generación Z, 2015); otros uno menor: desde 1990 hasta inicios de los 2000 (Igel, 2012), mientras que unos prefieren identificarlos simplemente como los nacidos después de 1990 (Braz, 2011) o después de 1995 (Jewell, 2014). En todo caso, parece más preciso situar su nacimiento alrededor del cambio de milenio (Acha, 2012). Sobre esta base tendremos una población cercana a los dos billones en el mundo actual, que puede ser identificada como parte de la generación $Z$, chicos y chicas que hoy pueden tener entre 15 y 19 años. Ellos se encuentran entonces en la adolescencia y el paso a la adultez, momentos que corresponden a una etapa en la vida marcada por una crisis en la cual expectativas, miedos y esperanzas se evidencian con mayor fuerza, entre otros cambios, que demandan del joven adolescente un esfuerzo de adaptación (Carcelén y Martínez, 2008).

Según Eronen (2000), esta etapa está marcada por momentos de transición, tales como la finalización de los estudios secundarios y el inicio de diferentes opciones de vida como adulto joven; el adolescente se enfrenta de manera inevitable a algunas tareas que la sociedad le plantea y, en términos generales, se espera que los jóvenes en esa etapa de su vida las lleven a cabo.

El término generación $Z$ se asigna debido a la tendencia al zapping (Braz, 2011), pero entendiendo al zapping no solo como el constante cambio de canales al ver televisión, sino como una tendencia constante al cambio; es decir, la incapacidad de hacer una sola actividad durante mucho tiempo. $\mathrm{O}$, si lo enfocamos positivamente, la habilidad de hacer muchas cosas a la vez (por ejemplo, escuchar música mientras se chatea con un amigo y se lee un texto académico).

\section{Características}

¿Qué diferencia entonces a esta nueva generación de las anteriores? Son diversas características las que van a configurar este nuevo grupo de jóvenes y aprendices.

Las primeras descripciones nos hablan de jóvenes hiperactivos, inmaduros, adictos a internet, interesados solo en lo que es relevante para ellos (Jaleniauskiene, 2015), sobreprotegidos porque los padres siempre les solucionaron los problemas (Cowan, 2014).

Tenemos una población sumamente variada $y$, por lo tanto, con una mayor tolerancia a la diversidad o "mente abierta". Hoy en día son cada vez menos extrañas las familias con padres del mismo sexo, las adopciones interraciales, la integración de los niños con alguna discapacidad física o mental, etcétera. La exposición regular a esta diversidad está logrando que los jóvenes sean cada vez más abiertos y tolerantes ante la realidad.

La generación $Z$ se caracteriza por su practicidad en todos los aspectos. Algo que podemos observar en las aulas universitarias es que para ellos leer o escribir textos "largos" resulta engorroso e innecesario. Por eso, vemos la proliferación de imágenes, emoticonos, memes, videos cortos, etcétera, que ahorran tiempo, si de asimilar contenidos se trata. Entre los 150 estudiantes de la Universidad de Lima nacidos en 1999, consultados a través de un cuestionario simple durante el curso "Desarrollo Personal y Social", 104 (el 65 \%) afirmó preferir el chat (WhatsApp, Messenger, entre otros) para comunicar algo sencillo. Solamente 22 (15\%) dijeron que preferían una conversación "cara a cara". Prefieren enviar un correo o un mensaje por WhatsApp para avisar o pedir permiso (Medina, 2015).

La omnipresencia de la tecnología en la vida de un joven perteneciente a esta generación es innegable. Según Lenhart, Smith, Anderson, Duggan y Perrin (2015), los estudiantes de la generación Z pasan un promedio de nueve horas al día en sus teléfonos. En este estudio, cuando se consultó a los estudiantes sobre su dedicación a las redes sociales, 40 de los 150 (27\%) afirmaron estar permanentemente mirando sus dispositivos para revisar redes sociales. Los nacidos en este marco generacional llegaron al mundo con la posibilidad de acceder a ver lo que ellos quieren en el momento que ellos quieren (Netflix, Youtube y otras plataformas así lo permiten), lo cual nos hace pensar sobre la capacidad que pueden tener de postergar gratificaciones o tolerar frustraciones en distintos ámbitos de su vida. La paciencia, definitivamente, no será un rasgo característico de la generación $\mathrm{Z}$.

Sin embargo, la tecnología, como recurso permanentemente presente, hace que estos jóvenes sean también más colaborativos en la búsqueda masiva de soluciones a través de comunidades en línea, que son cada vez más comunes, y esto impacta directamente en su forma de aprender, como veremos más adelante.

El rango de atención de ocho segundos en promedio (Shatto, 2016) nos habla de jóvenes que no permanecen dedicados a un tema o una tarea durante mucho tiempo, a menos que los motive real y profundamente. Esta característica marca un descenso de los doce segundos en que se mantenían atentos, en promedio, los millennials, y nos señala una tendencia a lo que Ratey llama "Desorden de déficit de atención adquirido". El proceso de enseñanza-aprendizaje, que siempre ha 
sido complejo y retador, se vuelve entonces un desafío enorme para los docentes de este grupo generacional.

Jewell (2014) describe a la generación Z como humildes, más sanos y preocupados por contribuir al bien social. Jóvenes muy prácticos que, frente a distintas situaciones, se preguntan cómo es que lo que sucede los involucra a ellos mismos ("¿qué tiene que ver eso conmigo?"). También podemos observar que la forma de comunicación ha variado de una generación a otra, y hoy en día, cada vez más, los jóvenes usan imágenes en vez de palabras, y son tan prácticos que muchas veces hablan en código (LOL, NTP, TBH, IDK, etcétera).

Esta practicidad es llevada también a la solución de problemas en su vida cotidiana, ya que no suelen invertir mucho tiempo o esfuerzo cognitivo en la atención de una situación problemática. La idea de la cual se parte es que siempre hay una aplicación ( $a p p$ ) o tecnología que ayuda, sin importar el tema o área del problema.

Si antes hubo una sobreexposición en redes sociales, la generación $\mathrm{Z}$ ha aprendido y es más consciente de la importancia de la privacidad (más Snapchat o Telegram, donde la información desaparece; menos Facebook o Twitter, donde la información permanece; menos uso de la geolocalización, usan alias en vez de nombres y apellidos, etcétera).

\section{Aprendizaje}

Hoy en día el conocimiento se encuentra, como solemos decir, "a un click de distancia". Los jóvenes de la generación Z lo saben mejor que nadie, pues toda su vida han buscado absolutamente todo lo que desean saber, ver, conocer, en el motor de búsqueda más usado en el mundo, creado por Larry Page y Sergey Brin en 1998 (justamente cuando se da el cambio generacional de millennials a generación Z). Ellos no conocen y probablemente tampoco imaginan un mundo sin Google, que les provee todas las respuestas, aunque la habilidad de seleccionar, validar o criticar la información que encuentran en línea es algo que debe ser entrenado aún.

El hecho de tener "toda" la información disponible, sumado a las características ya descritas, convierte a esta generación en aprendices visuales y muy prácticos. Entre los 150 jóvenes a los que se preguntó, 67 \% prefiere aprender a través de imágenes o videos, mientras el $11 \%$ prefiere textos y el $10 \%$, exposiciones. Sobre esta base, es lógico deducir que las clases magistrales o tradicionales cada vez resultan menos motivadoras para un estudiante.
Los profesores, entonces, se enfrentan a un reto: captar y mantener la atención de un alumno por más de diez segundos es una misión casi imposible. ¿Qué hacer ahora? Muchos docentes argumentan que lo tradicional no pierde vigencia y que no tiene nada de malo enseñar tal como nosotros aprendimos. Estas afirmaciones no solo demuestran poca capacidad de adaptación, sino también un mínimo interés en optimizar el proceso de enseñanza-aprendizaje.

Utilizar diferentes formas de tecnología en el aula es una forma de adaptarnos y acercar nuestra clase al estudiante. Pedir que realicen una búsqueda en internet, promover la colaboración a través de redes sociales, como Facebook, blogs, grupos de discusión online, entre otras, son maneras diversas en las que podemos incorporar herramientas tecnológicas que no solo motiven al alumno, sino también contribuyan al desarrollo de la asignatura.

Los videos son otra opción que debemos tener presente siempre (recordemos que son estudiantes predominantemente visuales), ya sea que se solicite una búsqueda o la elaboración de un material audiovisual relacionado con el tema del curso. Sin embargo, es muy importante recordar, para toda actividad que realicemos como docentes, la importancia de dar a los jóvenes de la generación $\mathrm{Z}$ un feedback inmediato o muy rápido; de lo contrario, pueden perder el interés o el enfoque en lo que se ha venido trabajando.

Las lecturas y las disertaciones no son dejadas de lado, ya que nunca dejarán de ser estrategias de enseñanza valiosas y enriquecedoras. Las lecturas (aquellas que son realmente necesarias y vinculadas al tema que se trabaja) pueden ser completadas en el dispositivo del alumno, para evitar la excusa de "no tengo el libro"; pues, como están digitalizadas, se encuentran siempre al alcance inmediato del lector. Las disertaciones pueden poco a poco tornarse más interactivas, estimulando la participación del alumno y el desarrollo de un pensamiento crítico en él.

El uso de estas y otras estrategias para incorporar la tecnología en una asignatura, sin embargo, no será viable si el docente no cree realmente en la utilidad de estas en el mundo educativo (Fernández-Cruz, 2016). Es complicado, además, que un docente que no maneja este tipo de herramientas las pueda aplicar, y mucho menos guiar a los estudiantes en un mejor uso de estas. Las carencias deben ser, poco a poco, subsanadas; a través de capacitación, actualización y exploración permanente, para desarrollar, así, competencias que reduzcan las brechas existentes entre profesores y alumnos. 


\section{Metodología de estudio}

\section{Planteamiento del problema}

- Pregunta de investigación:

¿Cuáles son las principales características de la generación Z de Lima en el 2017?

- Justificación de la investigación:

Esta investigación es importante porque permite conocer mejor a los estudiantes con quienes trabajamos, en cuanto a características, motivaciones, expectativas, entre otros aspectos.

\section{Objetivo}

Realizar una aproximación al conocimiento de la nueva generación de estudiantes de la Universidad de Lima (actuales o futuros), en cuanto a características cognitivas, afectivas y conductuales.

\section{Metodología}

- Diseño: Cualitativo-descriptivo.

- Muestra: Muestreo por cuota - Tres jóvenes nacidos a partir de 1999.

- Recojo de información: Entrevistas a profundidad.

- Técnica de análisis: Análisis de contenido.

\section{Análisis y resultados}

Las entrevistas se realizaron a tres adolescentes no relacionados entre sí. Uno de ellos (adolescente A) estudia quinto de secundaria en un colegio particular de Lima, el segundo (adolescente B) ha terminado la educación secundaria y se encuentra en etapa de preparación para su ingreso a la Universidad de Lima, y la tercera (adolescente C) cursa el segundo ciclo de Derecho en la Universidad de Lima. Las entrevistas fueron grabadas para facilitar el análisis y se utilizó un cuestionario base (anexo 1), sobre el cual se hicieron las repreguntas necesarias según cada caso. Los tres participantes firmaron un consentimiento informado (anexo 2), donde se les comunicó el objetivo y características de la investigación.
Adolescente A: El adolescente A (AA) se describe a sí mismo como un chico ansioso, impaciente, deportista, activo y extrovertido. Sobre su relación con la tecnología, afirma que esta no es tan importante para él, pues solo la usa para comunicarse con sus amigos a través de chats y alguna red social. No le gusta entrar mucho a Facebook porque lo siente "falso y posero", y además comenta que no le gusta publicar su vida. No tieneTinder ni Snapchat porque le parecen redes tontas y superficiales. No se siente dependiente del smartphone, pero sí le gusta tener un buen modelo de teléfono y plan de datos para acceder a lo que pueda necesitar de manera rápida; usa mucho el navegador de su smartphone para buscar información sobre cosas que no entiende, datos que requiere; como, por ejemplo, el teléfono de algún local, asuntos de ese tipo.

Al preguntarle sobre sus perspectivas de tiempo futuro, nos dice que le interesa estudiar una carrera que le permita ganar dinero para poder viajar y vivir tranquilamente. Piensa en administración de empresas o ingeniería industrial como posibilidades, pero aún no decide a qué universidad postulará. AA ve el trabajo o profesión como algo instrumental, una actividad que le va a permitir ser independiente y tener ganancias suficientes para vivir como desea. No cree que esté muchos años en una empresa, sino que va a ir probando y conociendo diferentes espacios laborales para ir creciendo cada vez más en este ámbito. No sabe si llegará a casarse y tener hijos porque no es algo que planifique en este momento.

Sobre su manera de aprender, afirma que le gusta trabajar en grupos pero también disfruta estudiando o haciendo tareas solo, mientras escucha música en su habitación. Cuenta que en el colegio donde estudia no usan mucho la tecnología y solamente pasan algunos videos de vez en cuando, pero son aburridos. Le gustaría que los profesores manejen y apliquen herramientas más interactivas, como plataformas virtuales o videos entretenidos que expliquen bien los temas. Piensa que su colegio es muy tradicional y que, tal vez, en la universidad pueda encontrar más tecnología aplicada a la educación.

Adolescente $B$ : El adolescente $B(A B)$ se describe a sí mismo como distraído, relajado, cariñoso, amiguero y muy pegado a su familia. $A B$ cuenta que la tecnología es muy importante para él, y que siempre está pendiente de lo que sucede en las diversas redes sociales, como Snapchat, Twitter, Facebook, etcétera, porque es su forma de divertirse y de interactuar con sus amigos. Sí comparte fotos e información de situaciones que vive cotidianamente porque al recibir comentarios o likes 
de estas publicaciones, siente que está conectado con amigos o familiares. Reconoce que a veces pasa mucho tiempo revisando su smartphone; pero siente que es algo común en estos días y que si no lo hiciera, se perdería de saber muchas cosas o se aburriría. Según afirma, su teléfono le soluciona la vida porque para todo recurre a él: buscar un número, apuntar algo, navegar en internet, chatear, etcétera. No lo usa para temas académicos.

Sobre sus metas o proyecciones, dice no encontrarse seguro de lo que quiere hacer porque no tiene claras sus fortalezas en cuanto a temas de estudios. Se está preparando para ingresar a una universidad privada porque sus padres le exigen que haga algo, pero en realidad le gustaría tener un año sabático para tomar una mejor decisión y definir mejor sus metas. En el futuro le gustaría tener un trabajo que no sea en oficina, sino en un área en la que pueda estar permanentemente en movimiento o en contacto con muchas personas diferentes. No le importa tanto el bienestar financiero, pero sí prioriza el llevar una vida con sentido y felicidad. Piensa que sí llegará a casarse y formar una familia, y espera hacerlo con su pareja actual, con quien tiene una relación desde hace dos años. Tienen proyectos y metas juntos, como ir a vivir en otras ciudades del país o en el extranjero.

En cuanto al aprendizaje, $A B$ dice que no le gusta estudiar, aunque ha tenido algunos profesores en el colegio con quienes sí ha disfrutado algunos cursos. Estos profesores eran muy cercanos, usaban un lenguaje coloquial y cercano con los alumnos, y enseñaban usando distintas técnicas o estrategias (proyectos, trabajos de campo, gráficos, entre otros). Comenta que le aburren los profesores que solo hablan en clases porque "se creen sabelotodos", cuando él piensa que todo lo que están diciendo en esas largas clases expositivas lo podría encontrar en Google. No sabe cómo será el aprendizaje en la universidad, pero no tiene altas expectativas, ya que tiene primos mayores que le han contado algunas experiencias y no son muy positivas.

Adolescente C: La adolescente C (AC) se describe a sí misma como sociable, responsable, conversadora, musical y práctica. Sobre la tecnología, siente que es un gran apoyo para todos los ámbitos de su vida. La usa para estudiar pues lee textos constantemente en sus distintos dispositivos, aprovechando los trayectos a la universidad, una cola en el supermercado o cualquier momento para avanzar en sus lecturas universitarias. También usa la tecnología para coordinar con sus grupos de trabajo, intercambiar archivos académicos con sus compañeros de clase y elaborar presentaciones o materiales académicos. En el ámbito social, la tecnología la mantiene vinculada con amigos a los que ya no ve hace tiempo o que se encuentran estudiando fuera del país. Utiliza las redes sociales para mantener estas conexiones y estar al tanto de lo que ellos hacen día a día, mientras comparte también algunas imágenes de su propia vida cotidiana. Todo esto la lleva a estar siempre mirando su smartphone o tablet; aunque afirma controlarse en clases, donde evita sacarlos de su bolso para no distraerse.

Sobre el futuro, tiene muy claras sus metas, pues se siente muy segura de la carrera elegida y piensa ingresar a realizar prácticas preprofesionales en el mediano plazo. Desea llevar una vida ordenada y tranquila, en la que pueda encontrar un balance entre lo económico y lo placentero. Quiere orientar su carrera a la responsabilidad social pues se siente muy comprometida con su entorno. Piensa casarse y tener hijos sin descuidar su desarrollo profesional, pero no tiene ningún apuro al respecto ya que siente que todo llegará en el momento adecuado.

Aprender siempre ha sido una experiencia gratificante para AC. Prefiere experiencias de aprendizaje activo, como dinámicas grupales o elaboración de proyectos, pero también se conecta bastante bien con charlas o exposiciones. Tanto en el colegio como en la universidad, se ha encontrado con profesores que manejan las herramientas tecnológicas, pero no las incorporan en clases, sino que se limitan a colgar las lecturas o presentaciones en el aula virtual y a utilizar algunos videos, eventualmente.

\section{Consideraciones finales}

Las entrevistas con los adolescentes muestran comportamientos y preferencias muy diferentes entre uno y otro (tiempo y tipo de uso de la tecnología, definición de metas), así como algunos elementos comunes (preferencia por aprendizaje activo, uso de dispositivos). No podemos ser ajenos al cambio y la evolución, pero tampoco podemos dejar de lado la individualidad del ser humano.

Entender a la generación Z, el modo en que aprenden y diseñar espacios de aprendizaje para ellos es complicado. Más aún si no existe voluntad de comprender y aceptar los cambios; nos falta tiempo o tenemos poca competencia en el mundo virtual.

El punto en el que debemos concentrarnos es el continuo crecimiento profesional y la voluntad de aprender junto a nuestros estudiantes, unos de otros. 


\section{Bibliografía}

AchA, R. (2012). Proyecto Z. Semana Económica, (28), 46.

Braz, A. (2011). Assertive social skills training for the elderly. Behavioral Psychology / Psicología Conductual, 19(2), 373-387.

Carcelén, M., y Martínez, P. (2008). Perspectiva temporal futura en adolescentes institucionalizados. Revista de Psicología PUCP, 26(2), 255-276.

Cowan P. A., y Cowan C. P. (2014). The Role of Parents in Children's School Transition. Encyclopedia on Early Childhood Development. Recuperado de http://www.child-encyclopedia.com/parenting-skills/according-experts/ role-parents-childrens-school-transition.

ERonen, S. (2000). Achievement and Social Strategies and the Cumulation of Positive and Negative Experiences During Young Adulthood. (Tesis doctoral, Universidad de Helsinki, Finlandia). Recuperada de https://helda. helsinki.fi/handle/10138/19760

Fernández-Cruz, F., y Fernández-Díaz, M. (2016). Los docentes de la Generación Z y sus competencias digitales/ Generation Z's Teachers and their Digital Skills. Comunicar, 24(46), 97-105.

Igel, C., y Urquhort, V. (2012). Generation Z, meet cooperative learning. Middle School Journal, 43(4), 16-21.

Jaleniauskiene, E., y JUCEVICIENE, P. (2015). Reconsidering University Educational Environment for the Learners of Generation Z. Social Sciences, 2(88), 38-53.

JEWELL, M. (2014). Generation Z. Gulf Daily News.

Lenhart, A., Smith, A., Anderson, M., Duggan, M., y Perrin, A. (2015). Teens, technology and friendship. Pew Research Center. Recuperado de http://www.pewinternet.org/2015/08/06/teens-technology-and-friendships/

Romero, R. (8 de octubre del 2016). ¿Cómo se le da el nombre a una generación? El País. Recuperado de https:// elpais.com/elpais/2014/10/08/icon/1412769513_110701.html

SHATto, B., Y ERWIN, K. (2016). Moving on From Millennials: Preparing for Generation Z. Journal of continuing education in nursing, 47(6), 253-254.

SLOTNISKY, D. (5 de mayo del 2012). Cómo internet está cambiando la forma en que funciona el cerebro humano. La Nación. Recuperado de http://www.lanacion.com.ar/1470127-como-internet-esta-cambiando-la-formaen-que-funciona-el-cerebro-humano

WilııAms,A.(20desetiembredel2015).MoveOver,Millennials,HereComesGenerationZ.NewYorkTimes.Recuperadode https://www.nytimes.com/2015/09/20/fashion/move-over-millennials-here-comes-generation-z.html? mcubz $=0$ 


\section{Anexos}

\section{Anexo 1. Instrumento}

- ¿Cómo se describe a sí mismo?

- ¿Qué objetivos tiene en la vida? ¿Qué quiere lograr? ¿Qué piensa sobre casarse o tener hijos?

- ¿Cuántos empleos (en organizaciones diferentes) cree usted que tendrá a lo largo de su vida profesional?

- ¿Qué medios sociales utiliza? ¿Cuánto tiempo al día pasa usted en redes sociales?

- ¿Qué tipo de contenidos busca en internet o medios sociales?

- ¿De qué manera prefiere comunicar algo sencillo a un amigo o familiar?

- ¿Qué siente cuando no hay wifi en un lugar y no tiene "megas"?

- ¿Cómo le gusta aprender?

- ¿Cómo ve a sus profesores universitarios y su uso de la tecnología?

\section{Anexo 2. Consentimiento informado}

Esta investigación tiene como objetivo conocer un poco más a las personas que nacieron a partir de 1999, conocidas como generación $Z$.

La entrevista tomará alrededor de treinta minutos y no implica ningún riesgo para el participante. La participación es voluntaria y lo que en ella se trate se mantendrá en reserva. Los nombres de los entrevistados no figurarán en ningún documento relativo a esta investigación.

Contacto: Mónica Soto, 987512670, msotod@ulima.edu.pe 